\title{
Ensino remoto e metodologias ativas na formação médica: desafios na pandemia Covid-19
}

\section{Remote teaching and active methodologies in medical education: challenges in the Covid-19 pandemic}

Luiz Severo Bem Junior ${ }^{1}$, Daniel Alencar de Andrade Campos ${ }^{1}$, Syana Monteiro de Alencar Ramos ${ }^{2}$ ${ }^{1}$ Faculdade de Ciências Médicas - Unifacisa, Campina Grande , Paraíba, Brasil.

${ }^{2}$ Licenciatura em pedagogia e mestrado em educação remota

\begin{abstract}
Resumo
O novo coronavírus vem afetando inúmeros setores, modificando nossas formas de interação e, no caso da educação formal, promove desconstruções sobre o processo ensino-aprendizagem, exigindo mudanças na metodologia. O objetivo deste trabalho é discutir sobre alguns dos desafios do ensino remoto e das metodologias ativas nos cursos de medicina na atual pandemia da Covid-19, adotados como estratégia para manutenção das aulas. Considerando as metodologias ativas, quais desafios docentes e discentes têm enfrentado no processo ensino-aprendizagem na medicina? Propomos instaurar o diálogo.

Palavras-chaves: Formação Médica. Ensino Remoto. Metodologias Ativas. Ensino-aprendizagem.
\end{abstract}

\begin{abstract}
The new coronavirus has been affecting countless sectors, modifying our forms of interaction and, in the case of formal education, it promotes deconstructions about the teaching-learning process, requiring changes in the methodology. The aim of this paper is to discuss some of the challenges of remote education and active methodologies in medical courses in the current Covid-19 pandemic, adopted as a strategy for maintaining classes. Considering the active methodologies, what challenges have teachers and students faced in the teaching-learning process in medicine? We propose to establish dialogue Keywords: Medical training. Remote Teaching. Active Methodologies. Teaching-learning.
\end{abstract}

\section{Introdução}

A formação médica é objeto de estudo importante no sentido de reinventar as práticas de produção da saúde e o fazer médico. A sociedade contemporânea demanda dos profissionais competências e habilidades, como colaboração em equipes multiprofissionais, autonomia intelectual, uso de linguagem apropriada e acessível frente às singularidades dos interlocutores e agilidade na tomada de decisões para resolver problemas do cotidiano. Além de qualidade técnico-científica, almeja-se que sejam médicos éticos, reflexivos e humanistas. 1,2

As propostas pedagógicas têm viabilizado a interação ativa do estudante com a população e com os profissionais de saúde desde o início da graduação, com o objetivo de proporcionar a oportunidade de trabalhar sobre problemas reais, assumindo responsabilidades crescentes como agente formulador e prestador de cuidados compatíveis com seu grau de autonomia.

Nesse contexto, as Metodologias Ativas oferecem aos estudantes oportunidades de construir seu conhecimento por meio de atividades teóricopráticas, de modo a aproximar a formação acadêmica da atuação profissional. Contudo, nos dias hodiernos com a vivência de uma pandemia que vem modificando drasticamente o comportamento da humanidade e de suas organizações, os profissionais de saúde em formação estão impossibilitados de interagir com os sujeitos, objetos e contextos de estudo. ${ }^{3}$ 
A Covid-19 é causada pelo agente etiológico SARS-CoV-2, que é um tipo novo de coronavírus, e surgiu inicialmente na China, em dezembro de 2019, sendo declarada pela Organização Mundial de Saúde (OMS) em janeiro de 2020 uma pandemia, se configurando como uma emergência de saúde pública de importância internacional. A Covid-19 possui um alto poder de transmissibilidade, podendo uma pessoa infectada transmitir, em média, a outros quatro indivíduos. ${ }^{5,6}$ Seus impactos ainda são inestimáveis, mas afetam direta e/ou indiretamente a saúde e a economia da população mundial.

Esse novo coronavírus vem afetando todos os países e criando a maior política de isolamento social da atualidade. Este promoveu transformações econômicas severas imediatas, com a parada obrigatória de inúmeros setores, modificou nossas formas de interação e, no caso da Educação formal, promoveu desconstruções sobre o processo ensinoaprendizagem socialmente influenciado. ${ }^{8}$

No âmbito educacional a excepcionalidade da situação levou inúmeros países a desenvolver ações de ensino remoto emergencial e as implicações nos diferentes níveis educacionais já começam a ser estudadas por pesquisadores brasileiros. No entanto, esse formato de ensino virtual ainda suscita muitas dúvidas e desafios.

Diante do exposto, o presente texto objetiva discutir sobre alguns dos desafios do ensino remoto e das metodologias ativas nos cursos de medicina na atual Pandemia da Covid-19.

\section{Ensino remoto e metodologias ativas na formação médica: alguns desafios}

Aprender é um processo individual e intrinsecamente pessoal. $\mathrm{O}$ ensino presencial ou à distância, possui três componentes: quem ensina, o aprendiz e o conteúdo. $^{15}$ Sob a visão tradicional, nos processos de ensino e de aprendizagem, o aprendiz tende a se colocar de forma passiva em relação ao mestre, permanecendo intelectualmente dependente, situação que deve ser desencorajada e estabelecidas metodologias para proporcionar uma conduta ativa no processo de aprendizado. $^{16}$

No Brasil, várias instituições escolares públicas e privadas atendendo a Portaria $\mathrm{n}^{\circ}$ $343 / 2020^{9}$ e a Medida Provisória No $934 / 2020^{10}$, substituíram as aulas presenciais por aulas em meios digitais. As instituições de ensino superior privadas buscaram implementar ensino remoto com aulas transmitidas em tempo instantâneo por sistemas de webconferências, permitindo que professores e alunos tenham condições de realizar interações e organizarem seus tempos de aprendizagem da forma mais próxima à educação presencial. $^{8}$

$\mathrm{O}$ ensino remoto praticado atualmente assemelha-se a Educação a Distância (EaD) no que se refere a uma educação mediada pela tecnologia. Porém, sem a estética da $\mathrm{EaD}$, os princípios seguem sendo os mesmos da educação presencial, com atividades síncronas e assíncronas. Aulas não presenciais assíncronas são aquelas em que o professor e o aluno não estão interagindo ao mesmo tempo. Já nas aulas síncronas, professores e alunos estão conectados ao mesmo tempo em uma " sala de aula virtual". ${ }^{17,18}$

Uma das grandes diferenças a serem apontadas entre abordagens presenciais e remotas é a descentralização do ensino, deixando de ser protagonizado pelo professor para se tornar focado no aluno.

A participação do aluno nos processos de ensino e aprendizagem é muito mais do que uma experiência de espectador, trata-se de uma experiência de cumplicidade e compartilhamento das atividades e seus resultados. O aluno deixa de ser um dependente intelectual e passa a exercer uma autonomia que o conduz para o autoestudo e ao discernimento de que o aprendizado seguramente depende, em grande parte, de seus próprios esforços e motivações pessoais.

Dentre os desafios que emergem nessa realidade está a ausência de políticas públicas para enfrentar a falta de acesso técnico a equipamentos e ampliar a equidade no processo de ensino aprendizagem. No ensino superior privado é possível perceber menos resistências à implementação de tecnologias digitais no processo de ensino e aprendizagem. No curso de medicina, por exemplo, a implementação da educação remota emergencial conta com número significativamente reduzido de pessoas sem acesso às tecnologias digitais. Mas emergem outros desafios. ${ }^{12}$

A inserção de novas tecnologias pressupõe enfrentar o desafio de desenvolver novas competências para as quais nem todos os discentes e docentes estão preparados. Como a prática pedagógica recorrente no ensino nos cursos de 
medicina é presencial, talvez não se tenha estimulado os professores à "alfabetização digital", ao domínio de metodologias e estratégias de ensino que promovam uma autonomia, um empoderamento e uma autodeterminação do estudante em relação aos estudos mediado pelo Ensino Remoto.

Outra questão já outrora apontada é que nem todo professor de medicina tem conhecimentos pedagógicos, resultando algumas vezes em aulas cujo foco são as transmissões de conteúdos e na avaliação numa concepção quantitativa. Em se tratando de ensino, é evidente que o docente possui um papel a cumprir, mas não pode ser entendido como agente exclusivo no processo dialógico de ensinar e aprender. ${ }^{13}$

Contrariamente, defendemos que o professor deve criar possibilidades para a produção do saber. Assim, o estudante deve ser compreendido e estimulado a ser também responsável por sua formação intelectual.

O enfoque curricular Ciência, Tecnologia e Sociedade (CTS) adequa-se a essa proposta, pois pauta-se na experiência do aluno e inclui aspectos humanos e sociais da Ciência, possibilitando a tríade "Ciência-Tecnologia-Sociedade", cujos focos principais são: a) aquisição de conhecimentos; b) utilização de habilidades; e c) desenvolvimento de valores. $^{14}$

Desde os anos 1990, os cursos de graduação em medicina no Brasil passaram a adotar as Metodologias Ativas no intuito de mobilizar estudantes para a participação ativa no processo de ensino-aprendizagem, ressignificando o papel do professor como mediador em busca de uma formação médica, embasada pelas políticas públicas nacionais e internacionais. Essas abordagens curriculares se fundamentam nos princípios da aprendizagem ativa e significativa:

(a) a resolução de problemas por meio da articulação entre os campos profissional e acadêmico;

(b) o desenvolvimento de conhecimentos transversais por meio da atuação em equipes; $\mathrm{e}$

(c) a complexidade dos conhecimentos, e atividades pautadas na multidisciplinaridade ${ }^{1}$.

A partir da orientação realizada pelos professores e da participação ativa em atividades situadas e reais do seu (futuro) campo de trabalho, os acadêmicos constituem sua autonomia na esfera acadêmica e participam de práticas características tanto da universidade quanto do mundo do trabalho.

Diante das atuais condições dadas de pandemia e incertezas, os estudantes de medicina que vivenciam seu processo de aprendizagem de forma passiva encontram ainda mais dificuldades, pois a educação médica é complexa e precisamos estimular os estudantes a aprender e a ser sujeito neste processo.

\section{Considerações finais}

Os espaços-tempos formativos se constituem como um lócus de embates constantes entre as escolhas políticas, éticas e pedagógicas. Nesse contexto de pandemia, a formação no ensino superior se modificou não só pela suspensão das aulas presenciais, mas também pela maneira de se fazer a $\mathrm{EaD}$ no ensino remoto, com impacto na rotina de ensino e aprendizagem de discentes e docentes e exigindo uma postura ativa do estudante.

\section{Referências}

1. Costa NMSC (2010). Formação pedagógica de professores de medicina. Rev. LatinoAm. Enfermagem. 18, 1: 102-108.

2. Venturelli J (2003). Educación médica: nuevos enfoques, metas y métodos. Washington, D.C. Organización Panamericana de la Salud/Organización Mundial de la Salud; $2^{\mathrm{a}}$ ed.

3. Valente JÁ (2019). Tecnologias e educação a distância no ensino superior: uso de metodologias ativas na graduação. Trabalho \& Educação, 28, 1, p. 97-113.

4. Castaman AS, Rodrigues RA (2020). Educação a Distância na crise COVID - 19: um relato de experiência. Research, Society and Development, 9, 6, e180963699.

5. Organização Mundial Da Saúde. Folha informativa - COVID-19 (doença causada pelo novo coronavírus). 2020.

6. Bristol University. Coronavirus (COVID-19): advice and information. Disponível em: https://www.bristol.ac.uk/students/coronavirus/.

Acesso em: 27 maio 2020. 
7. Ministério da Saúde (BR). Plano de contingência nacional para infecção humana pelo novo coronavírus Covid-19. Brasília: Ministério da Saúde; 2020 [acesso 25 maio 2020]. Disponível em: https://portalarquivos2.saude.gov.br/ images/pdf/2020/marco/25/Livreto-Plano-deContingencia5-Corona2020-210x297-16mar.pdf

8. Ribeiro M, Júnior DGA, Cavalcante ASP, Martins A, Sousa L, Carvalho R \& Cunha ICKO (2020). (RE)Organização da Atenção Primária à Saúde para o enfrentamento da COVID-19: Experiência de Sobral-CE. APS em revista, 2(2), 177-188. https://doi.org/10.14295/aps.v2i2.125

9. BRASIL. Portaria $\mathrm{N}^{\mathrm{o}} 343$, de 17 de março de 2020. Dispõe sobre a substituição das aulas presenciais por aulas em meios digitais enquanto durar a situação de pandemia do Novo Coronavírus - COVID-19. D.O.U 18/03/2020.

10. Brasil (2020b). Medida Provisória $N^{\circ} 934$, de $1^{\circ}$ de abril de 2020. Estabelece normas excepcionais sobre o ano letivo da educação básica e do ensino superior decorrentes das medidas para enfrentamento da situação de emergência de saúde pública de que trata a Lei $\mathrm{n}^{\circ} 13.979$, de 6 de fevereiro de 2020. Recuperado em 02 de abril, 2020, http://www.gov.br/en/web/dou/-/medidaprovisoria-n-934-de-1-de-abril-de-2020-250710591

11. Santos Junior VB, Monteiro JCS (2020). Educação e covid-19: as tecnologias digitais mediando a aprendizagem em tempos de pandemia. Revista Encantar - Educação, Cultura e Sociedade - Bom Jesus da Lapa, 2, 01-15, jan./dez.

12. Arruda EP (2020). Educação remota emergencial: elementos para políticas públicas na educação brasileira em tempos de Covid-19. EmRede, 7, 1, 257-275.

13. Moreira JÁ (2020). Por um novo conceito e paradigma de educação digital onlife. Revista UFG, 20,63438

14. Cerezo, JAL (2002). Ciência, Tecnologia e Sociedade: o estado da arte na Europa e nos Estados Unidos. In: SANTOS, L. W. (Org.). Ciência, tecnologia e sociedade: o desafio da interação. Londrina: IAPAR, p. 3-38.

15. Eduardo Chaves. Tecnologia na educação, ensino à distância, aprendizagem mediada pela tecnologia: Conceituação básica. Revista Educação da Faculdade de Educação da Pontifícia Universidade Católica de Campinas, (7), Novembro 1999.

16. Maria da Graça Nicoletti Mizukami. Ensino: As abordagens do processo. Pedagógica e Universitária LTDA - EPU, 1986

17. Rena M. Palloff and Keith Pratt. O Aluno Virtual: Um guia prático para trabalhar com estudantes on-line. Editora Artmed, RS, 2004.

18. José Armando Valente. Educação a Distância no Ensino Superior: Soluções e Flexibilizações. Interface - comunicação, saúde, educação, volume 7. Fevereiro 2003

Autor para correspondência Luiz Severo Bem Junior luizseverojunior@yahoo.com.br

Recebido: 15/6/2020Ａceito: 30/06/2020 